\title{
Blended Learning Model: A Practical Approach for the Professional Development of University Students in Cameroon
}

\author{
Kibinkiri Eric Len \\ The Higher Teacher Training College, University of Yaoundé I, Yaounde, Cameroon \\ Email: kibinkirieric@yahoo.com
}

How to cite this paper: Len, K. E. (2019). Blended Learning Model: A Practical Approach for the Professional Development of University Students in Cameroon. Creative Education, 10, 583-599. https://doi.org/10.4236/ce.2019.103042

Received: January 25, 2019

Accepted: March 12, 2019

Published: March 15, 2019

Copyright (อ 2019 by author(s) and Scientific Research Publishing Inc. This work is licensed under the Creative Commons Attribution International License (CC BY 4.0).

http://creativecommons.org/licenses/by/4.0/

\section{(c) (i) Open Access}

\begin{abstract}
The consistent increase in student population in university campuses without a corresponding infrastructural development and consequently limited professional competences developed motivated the researcher to carry out this study. Related literature based on blended learning, distance education and professional development constituted the conceptual framework of the work. The Goal Theory and the Theory of Change were used to give meaning to the problem of study. Qualitative approach was applied to carry out the study. The target population consisted of graduates of the Distance Education programme (2016/2017 graduation batch). The accessible population was made up of graduates of Yaounde Study Centre. Interviews were carried out with eight (8) cases that were selected using purposeful sampling technique. The data collected were analysed thematically following the objective of the study. Overall results of the study revealed that the blended learning model influenced professional development of university students in Cameroon. The results have shown that students are more comfortable with face-to-face learning mode as compared to online learning mode and self-learning mode. Consequently, recommendations are made to universities to adopt this model in their training programmes.
\end{abstract}

\section{Keywords}

Blended Learning, Face-to-Face Mode, Online Learning, Self-Learning, Social Presence, Cognitive Presence, Teaching Presence, Professional Development

\section{Introduction}

Higher education in Cameroon is receiving growing attention and interest from 
the government. The country is making tremendous efforts to improve the quality and quantity of higher education offered to its students. Since 1993, the government has increased the number of universities and institutions of higher learning across the country. These institutions are created to build human capital that can assist in the transformation of the country. Institutions that are already well established are undergoing transformations in order to meet the growing needs and expectations of the students and the society. It is worth noting that between 1960 and 1993, government was able to provide full scholarships for university students because of the need for human capital at the time. After the 90s, parents started paying fees for their children with the expectation that upon graduation from the university they were going to get white collar jobs. Unfortunately, this is not the case for many students who find it difficult to get jobs after graduation, notwithstanding the government assists students in different ways, for example provision of computers and award of excellent grants. These measures are laudable; however, they are insufficient. The curriculum of our universities is still not well adaptable for the current trends in higher education. One of the solutions to the myriad problems encountered by students in the university can be a complete revision or change in the instructional paradigm. Thanks to recent developments in education like the introduction of information and communication technologies, new strategies and methods of content delivery and assessment that can meet the needs, aspirations of the youths can be tested. In this respect, the blended learning model has the potential to transform higher education in Cameroon.

Concerning the school going population, there is a high sensation among youths between the ages of 17 and 40 for university education. This group of learners needs to develop professional competences that can make them more useful to their communities. Access to basic education is financed to a large extent by the government. The successes registered at basic education in terms of access have partly contributed to a remarkable increase in school going population at the other levels. Many are of the opinion that higher education can guarantee better jobs in future. Today, the greatest challenge facing higher education is how to accommodate and manage the large numbers of students in university campuses hungry for knowledge and help them develop professional competences. The unprecedented increase in numbers has led to a decline in the quality of teaching and learning. As a consequence, many graduates are finding it difficult to get jobs or create employment for themselves.

\section{Conceptual Framework}

\section{Blended Learning Model}

Blended learning model in this study refers to the use of a combination of instructional delivery approaches such as face-to-face mode, online learning mode and self-directed learning mode in distance education. The model derives its meaning from the concept of eLearning. Naidu (2003: p. 8) defines e-Learning as 
"the systematic use of networked information and communication technology in teaching and learning". According to Noe (2002), blended learning means "the use of a combination of online learning, face-to-face instruction, and other methods for distributing learning content and instruction". Educational institutions across the world are positioned at different points on the road map between campus- or classroom-based learning and web-based learning (Perkinson, 2005; Rwagasana \& Stucki, 2009). The evolution of eLearning depends to a great extent on access, subscription or ownership and use of information and communication infrastructure especially the Internet (World Bank, 2006). According to Noe (2002), many institutions across the world are moving to a hybrid approach because of the limitations of online learning related to insufficient bandwidth, learners' preference for face-to-face contact with instructors and other learners. Figure 1 presents the path that many higher education institutions in both developed and developing countries are traversing towards cost-efficient web-based delivery.

\section{Face-to-face Learning Mode}

Face-to-face Learning refers to the teaching learning process in which students are in the classroom on seat with the teacher. It is also called on-campus delivery mode. The teacher can bring Internet sites of relevance and interest into the classroom. Students can also access topics or course materials using multimedia technologies, but do not replace traditional teaching methodologies.

\section{On-Line Learning Mode}

On-line learning mode or delivery is located at the more advanced end of the continuum, where students access either intranet-based or internet-based learning objects (distributed learning systems), downloading topics or course materials and contacting tutors and each other entirely over the Web. Naidu (2003) pointed out that eLearning appears to be growing out: "from within educational institutions, which have offered open and distance learning programs either in a single, dual, or mixed mode".

\section{Self-Learning Mode}

In this study the self-learning mode is synonymous to self-directed learning. According to Knowles (1975) cited in Guglielmino \& Guglielmino (2004), self-directed learning refers to "a process in which the learner, with or without the help of others, identifies learning needs, defines learning goals, develops and implement a learning plan and evaluates the learning gained”. Latchem (2012) viewed that when learners engage on self-directed learning, they take responsibility for their learning and are able to plan and organize this learning. The learners who are most likely to be successful in this process are those who have the highest levels of readiness for self-directed learning: a complex mixture of

$$
\text { Face-to-face(No e-Learning)——_Blended Learning — Web-based Learning }
$$

Figure 1. Continuum towards web-based learning. 
knowledge, skills, attitudes and habits (Guglielmino \& Guglielmino, 2004). Sagna (2005: p. 51) holds that people learn effectively by pursuing realistic goals, which are also intrinsically motivating and that learning is greatly enhanced when it is anchored or situated in meaningful and authentic problem-solving contexts.

\section{Theoretical Framework}

\section{Goal Theory}

Goal theory is relevant in curriculum design and can be applied to the blended learning model and professional development of university students in Cameroon. Locke (1968) found that individuals who set specific challenging goals performed better than those who set general or vague, unchallenging goals. $\mathrm{He}$ demonstrated that employees are motivated by clear, well defined goals and feedback. According to Locke (1968), employees are less likely to be committed to a goal if they believe it is too difficult. The process of curriculum reengineering can be facilitated by providing the main stakeholders like the curriculum worker, teachers, students, parents, non-governmental organisations and entrepreneurs with specific challenging goals and objectives. This process of goal setting should be a collaborative and all-inclusive effort. The influence of goal setting theory can be seen in the development of curriculum plans.

\section{Theory of Change}

Kurt Lewin's Theory of Change explains organisational development. This theory is relevant and can be applied to blended learning model and professional development of students in higher education. Theory of Change is a methodology for planning, participation and evaluation used to promote social change (Kritsonis, 2004-2005). It explains the process of change by outlining causal linkages in an initiative that is its short-term, intermediate and long-term outcomes. The innovation of this theory as compared to goal setting theory lies in making the distinction between desired and actual outcomes and in requiring stakeholder to model their desired outcomes before they decide on forms of intervention to achieve those outcomes. The theory is also a critical theory which requires diverse perspectives and participation in order to create solutions. An important component linked to this theory is change management. Noe (2002) defines change management as the process of ensuring that new interventions such as training practices are accepted and used by employees and managers. According to him, change management involves four steps: overcoming resistance to change, managing the transition to the new practice, shaping political dynamics and using training to understand new tasks.

Despite much effort put in to higher education by the government, a lot is still needed to be done in terms of the professional development of its graduates. The value of one's education can only be judged by the contributions made to the society during and after school. The study aims to answer the question "to what extent does the blended learning model influences the professional development of university students in Cameroon?” The researcher's experience over the years 
as a lecturer in the Higher Teacher Training College helped him to operationalize the variables of the study. Blended learning model in the study is defined by three main constructs (face-to-face learning mode, online learning mode and self-learning mode).

\section{Research Methodology}

This study was carried out in Cameroon specifically in Yaounde with distance education students of the University of Buea (Yaounde Study Centre). Cameroon has eight state universities. University of Buea is one of them. This university was created in 1993 as the first Anglo-Saxon University in Cameroon. It is located in Buea the capital of the South West Region of Cameroon. Today, the University of Buea offers distance education through its Faculty of Education. This programme officially started in 2008/2009 academic year. According to the programme coordinator Dr. Alemnge Fidelis, distance education in the Faculty of Education is aimed at upgrading the knowledge and skills of teachers of Nursery and Primary schools to degree level (Alemnge, 2015). The programme offers professional competences for students who want to become teachers as well as teachers of nursery and primary education to earn a Bachelor of Education degree in Nursery and primary education after four years. It is primarily print based and tutorials are delivered face-to-face in study centres in different regions of the country. This is reinforced by telephone tutorials in between the tutorial sessions. Tutorials are organized two times in a semester for a maximum of one week respectively. Assessment is based on continuous assessment in the form of two take home assignments which counts for thirty percent of the marks and an end of semester examination which covers the remaining seventy percent of the marks. The programme is sustained by fees paid by students. The first batch of students graduated in the 2011/2012 academic year. According to Alemnge (2015), Students who succeed to get admissions need to score at least 180 credits after eight (8) semesters in four years to qualify for graduation from the programme.

The target population consisted of graduates of the Distance Education programme (2016/2017 graduation batch). The accessible population was made up of graduates of the Yaounde Study Centre. The choice of Yaounde Study Centre was because the researcher was the Centre manager and has been tutoring and coordinating the activities of the distance education students for more than five (5) years. Eight graduates were chosen for the study. Purposive sampling technique was used to select the cases studied.

Table 1 shows that there are eight (8) cases studied. That is Case A, Case B, Case C, Case D, Case E, Case F, Case G and Case H. Table 1 also reveal that one of the participants was a teacher in a private school while the others were teachers in a public or government schools. Three (3) participants were from the South West Region of Cameroon while five (5) respondents were from the North West Region of Cameroon. Of the eight participants, four (4) were females and 
Table 1. Socio-demographic characteristics of the participants.

\begin{tabular}{|c|c|c|c|c|c|c|}
\hline Case & Type of School & Name of School & Region & Gender & Experience & Qualification \\
\hline Case A & Private & Queensway Bilingual school & North West & Male & 22 years & B.Ed. \\
\hline Case B & Public & Government Bilingual Primary School Nkolndongo Mbida & South West & Male & 16 years & B.Ed. \\
\hline Case C & Public & Ecole Primaire d'application Camp Bove II A & North West & Male & 15 years & B.Ed. \\
\hline Case D & Public & Government Primary School Essos II & North West & Female & 18 years & B.Ed. \\
\hline Case $\mathrm{E}$ & Public & G.B.P.S Essos group II & South West & Female & 19 years & B.Ed. \\
\hline Case F & Public & Government Bilingual Primary school mbai mboum & North West & Female & 8 years & B.Ed. \\
\hline Case G & Public & Government & South West & Male & 9 years & B.Ed. \\
\hline Case $\mathrm{H}$ & Public & Government Bilingual Primary School Figuil & North West & Female & 10 years & B.Ed. \\
\hline
\end{tabular}

four (4) were males. As per professional qualification, they were all holders of the teacher's grade one certificate (CAPIEMP) and Bachelor of Education (B.Ed.). Their teaching experiences ranged from 8 to 22 years. The method used for data collection was interview. A semi structured interview guide was carefully constructed following the main objective of the study to collect data. Interview permitted the participants to express themselves freely to provide sufficient information for the study. Each interview took about one hour. The interviews were carried out in December, 2017 at the Higher Teacher Training College in the researcher's office. This environment was considered appropriate for the collection of data. The data collection process began with a presentation of the project to the participants, its objectives and assurance of confidentiality of information to be provided. Information provided was recorded using a digital camera. Each interview was transcribed. Transcription was done by listening carefully to the recorded information in audio format and writing down every word that was used by the participants. This process was repeated several times to avoid leaving out some vital information. The transcribed interviews were typed in a tabular form, printed out and read as many times as possible to crosscheck if there was any useful information left out. Data was analysed using content analysis. The data collected was categorized according to the themes and sub-themes which defines the study.

\section{Presentation of Findings}

\section{Face-to-Face Learning Mode (F-FLM) and Professional Development}

Case A: Concerning face-to-face learning mode, the participants interviewed were able to provide answers to all the questions that were asked in relation to this construct of blended learning. On his part, Case A stated that Social presence during Distance Education (DED) tutorials can be summarized in one sentence as the affective dimension of the tutorials. Social presence during DED tutorials contributed to my professional development in that; it demystified the phobia of public speaking, it built my capacity to argue logically, it helped us in general to have psychological authority in class. Case A further stated that, Cog- 
nitive presence during DED tutorials is the level of thought or thinking that the tutorials helps one to develop. Cognitive presence opens up the mind to think in various directions, one can easily move from subjective thinking to objective thinking. Still on the question of face-to-face learning mode, Case A viewed that Teaching presence is when one attempts to put on the shoes of the learner and give the best he or she can to explain concepts. Teaching presence can influence professional growth in that one will always want to be innovative and move beyond existing norms to bring out the best".

Case B: According to Case B, Social presence during DED tutorials is interaction between the learner and the instructor in a confined environment. When asked about its contribution to professional development, Case B responded that it has contributed to my professional development in terms of teaching style, dressing code, and above all a change of attitude from seeing learners as empty vessels to seeing learners as full of knowledge that just need to be awaken. On the aspect of cognitive presence during DED tutorials, Case B pointed out that this is the tendency to be able to grasp material presented as the instructor interacts with the learner or gives lectures. The learner reflects on this, think how this can be put into practice, what the outcome could be. As for teaching presence during DED tutorials, Case B stated that it is the physical presence in class. During tutorials, the instructors are physically present and give room for questions, answers and personal experiences and opinion. There is no doubt that teaching presence facilitates learning during tutorials.

Case C: According to Case C, social presence during tutorials refers to feeling of togetherness between students and students as well as instructors. The feeling of belonging during DED tutorials helped to develop my social interaction with friends thinking and public speaking. Cognitive presence is the thinking and reflection of students during tutorials. Cognitive presence or thinking during DED tutorials helped to open my mind to reflect and think critically, solve problems from simple to complex, developed in me spirit of hard work towards the teaching profession and the quest for more knowledge. Teaching presence refers to interactions between the learners and the tutor during tutorials. Teaching presence helped me to engage in many learning activities even without the presence of an instructor or teacher.

Case D: According to Case D, social presence in class helped me to acquire more knowledge and to interact with friends and teachers. It contributed to my professional development in many ways. It helped me to have good grades in my exams. The course materials were being explained in detail, line after line to my understanding. This upgraded my teaching back in the classroom. As concerns cognitive presence during DED tutorials, this simply refers to the levels of acquisition of new knowledge. The new knowledge I acquired has helped in my professional development. I teach without stress. My class is child centred. I have learnt how to use my tenses. As for teaching presence during DED, the course outline was well structured and easy to understand. I have cultivated the habit of reading alone. The facilitators taught with teaching aids. This made our lessons 
interesting. The units ended with questions which facilitated our learning process.

Case E: Case E defined social presence during DED tutorials as the feeling of belonging in the class or group during tutorial session. Social presence during tutorials has helped to increase my level of interactions, scope of learning and thinking. Concerning cognitive presence during DED tutorials, Case E said that this refers to deep reflection and thinking processes during tutorials. It helped me to teach without fear and stress as I have mastered what teaching is all about. On the question of teaching presence during DED tutorials, Case E responded that it is the facilitation of learning during the session by the tutor. This helped me to be innovative and search for more knowledge.

Case F: On her part, Case F defined social presence during DED tutorials as the ability to identify with the class or course, connect and interact with others as real people through the medium of communication being used in a way that promote learning during tutorials. When asked about its contribution to professional development, Case F responded that it contributed to my professional development in that, with the availability of tutorials, I learnt to collaborate with other classmates. On the aspect of Cognitive presence during DED tutorials, Case $\mathrm{F}$ answered that it is the extent to which learners are able to construct meaning through critical thinking during tutorials. Concerning teaching presence during DED tutorials Case F responded that it is the instructional relationship tutors have with their students, where the instructor serves a fundamental leadership role in facilitating and managing the course. When asked about its contribution to professional development, the response was "I have learnt to prepare and deliver my lessons well so that my learners can become better learners today and, in the future".

Case G: On his part, Case G defined social presence during DED tutorials as communication between people in a given environment to foster personal and purposeful relationships. This helped me to develop a sense of belonging in distance education. On the question of cognitive presence during DED tutorials, Case $G$ stated that this refers to critical thinking in the course of exchange through a medium or a foru, in order to be able to provide solutions to problems. He further explained that "critical thinking during distance learning reinforces the learner's ability to analyze and construct meaning in order to solve problems posed in the classroom. On the aspect of teaching presence during DED tutorials, Case $G$ viewed that this refers to instructional design and facilitation of learning".

Case $\mathrm{H}$ : On her part, Case $\mathrm{H}$ pointed out that social presence during tutorials is more of a combination of factors that contribute to develop greater intimacy within a group. Thanks to social presence during DED tutorials, I learnt how to communicate well with learners. I am able to understand the needs of my learners, construct and maintain discipline in my class, and communicate with a lot of confidence and fluency. On the aspect of Cognitive presence during DED tutorials, Case $\mathrm{H}$ pointed out that this refers to the discussions that encourage students to explore and apply key ideas and resources to situations from familiar 
experiences. When asked about its contribution to professional development, Case $\mathrm{H}$ stated that she is now able to select learning activities that stimulate intellectual curiosity about content and concepts. I am also able now to provide discussions that engages learners to critical thinking and analyse different perspectives related to a given concept or problem of study. Concerning teaching presence during DED tutorials, Case $\mathrm{H}$ stated that it is the instructor's ability to facilitate the mastery of content in class by providing appropriate directives and guidance during tutorials in order to facilitate learning. When asked about its contributions, Case $\mathrm{H}$ answered that I make sure I serve as a model that my learners can emulate during tutorials. I also make sure I prepare my lessons well ahead of time before the tutorials.

\section{Online Learning Mode (OLM) and Professional Development}

Concerning Online Learning Mode (OLM), the participants presented their views with respect to the different elements which defined this construct.

Case A: According to Case A, online social presence means that the learner and the instructor are not close to each other but linked by the Internet. When asked about its contribution, the answer was that virtual or online presence has contributed positively to my professional development in distance education in that I now see beyond the immediate surroundings. Concerning virtual cognitive presence, Case A stated that it simply means that the learner and the instructor are not in the same facility but the learner perceives all what the instructor gives through the internet. When asked about its importance, Case A pointed out that virtual cognitive presence enlarges your scope of thought, makes you see what others see and more. On the aspect of online teaching presence, she responded that it simply refers to the use of the Internet in learning especially in teaching teachers. To him, virtual teaching presence changes your approach to learning and teaching as a result of its simplicity in terms of use.

Case B: To Case B, Social presence in an online learning process is simply learning in which the learner and the instructor do not interact physically. To him, online social presence has actually done much as far as the feeling of belonging in the learning process is concerned. He further explained that modern technology has contributed to my professional development in the sense that it has developed my zeal of learning faster and less costly. Case B viewed cognitive presence in an online learning process as imagining or thinking about what you are receiving from distance education. When asked about its importance to professional development, the response was that Virtual cognitive presence has increased my listening ability as well as my thinking capabilities. On the aspect of online teaching presence, Case B stated that this refers to the process of receiving instruction from an instructor far from you.

Case C: As for Case C, social presence in an online learning process refers to Social interactions between the learner and the instructor through information and communication technology for example Internet. When asked about its importance to professional development, the answer was that virtual social presence has helped me in distance education to be used to the Internet, to master 
how to search for theories of teaching and learning online without the presence of the instructor. On the aspect of cognitive presence in an online learning process, Case $\mathrm{C}$ pointed out that this refers to the thinking and reflection of students and teachers through the internet or other ICT media. When asked about its contribution to professional development, she responded that cognitively, virtual or online learning has helped to widen my scope of thoughts especially in the teaching domain. As concerned teaching presence in a virtual learning process, Case $\mathrm{C}$ viewed that this refers to the process of facilitating learning online through the use of media like teleconferencing. When asked about its importance, the response was that virtual teaching presence has changed my approaches to teaching such as methods, theories and strategies.

Case D: Still on the construct of Online Learning Mode, Case D stated that Social presence in an online learning process refers to the interactions that occur online or when using the computer. When asked about its importance to professional development, the answer was that the use of computer assists in instruction and learning and therefore improves on professional development. On the aspect of cognitive presence in an online learning process, Case $\mathrm{D}$ pointed out that cognitive presence helps in the conception of new ideas and knowledge acquisition He further explained that cognitive presence helps in many ways to achieve a wide range of educational goals, facilitates the learning of content and mastery of skills. It helps build learner interest in course materials. Concerning teaching presence in an online learning process, Case D pointed out that it is simply the process of facilitating learning with the internet. On the question about its importance, the answer was that virtual teaching presence helped me to acquire skills, concepts and knowledge on how to develop the learning content.

Case E: On her part, Case E defined Social presence in an online learning process as the feeling of belonging through the internet. Concerning its contribution to professional development, Case E responded that virtual social presence has motivated her to develop interest in using the Internet for research. On the aspect of cognitive presence in an online learning process, Case E viewed cognitive presence as reflection and thinking when using the internet. When asked about its importance to professional development, Case $\mathrm{E}$ responded that virtual online cognitive presence has helped her to build positive thinking towards distance education. Concerning teaching presence in an online learning process, Case E stated that this refers to the facilitation of learning through the Internet. When asked about its contribution to professional development, she responded that virtual teaching presence has increased her knowledge on the methods of teaching in the classroom.

Case F: According to Case F, social presence in an online learning process is the ability of participants in a community to project themselves socially and emotionally as real people through a medium of communication. It has helped me to know more about other students learning patterns and has given me the chance to interact with my instructors in my field. On the aspect of cognitive presence, Case $\mathrm{F}$ pointed out that cognitive presence in an online process refers 
to the quality and quantity of critical thinking, collaborative problem solving, and construction of meaning occurring in student and student faculty interactions through a medium of communication. When asked about its contribution to professional development, Case F responded that it has helped to improve on my thinking when faced with a thought provoking question or problem. Concerning teaching presence in an online learning process, Case $\mathrm{F}$ viewed it as the design, facilitation and direction of cognitive and social processes for the purpose of realizing personally meaningful and educationally worthwhile learning outcomes through a medium of communication. In this educational experience, teachers and learners have important complimentary responsibilities in the learning process. When asked about its importance to professional development, the response was that it has influenced my professional development in DED as it has improved my abilities to deliver lessons without major difficulties.

Case G: Still on the Online Learning Mode, Case G stated that Social presence online has to do with communication between people using the Internet. $\mathrm{He}$ further explained that communication through an electronic medium lead to the establishment of personal and purposeful relationship, which develops the sense of belonging in distance education. This sense of belonging motivated and encouraged me. It also helped me to access learning resources like documentations that are difficult to find locally. These made studies more effective as it facilitated communication in classroom activities. Cognitive presence refers to critical thinking in the course of exchange through an electronic medium or forum thanks to Internet connection. This helped me to develop abilities in analyzing classroom activities and discussions. Teaching presence has to do with instructional design and organization, facilitation of discussions and giving direct instructions through a computer medium. I have been able to design instructions and facilitate organized discussions in my classes by using the direct instruction skills acquired through online learning. Today technologically designed instructions are being used in my classes through social media discussion forums. These skills have in return made my practical classroom instruction productive.

Case H: Case H defines online social presence as learners' abilities in a community to project themselves, socially and emotionally as real people through a medium of communication. It has contributed to my professional development in distance education in that, it provides me access to interact freely with my peers, colleagues and my lecturers to discuss and share ideas especially during project writing. Cognitive presence in virtual learning process refers to the extent to which learners are able to construct meaningful learning in a critical community of inquiry. It influenced my professional development in that when a problem is identified for inquiry, it is explored both individually and collectively, through critical reflection and discourse. Learners construct meaning through shared ideas. They draw resolutions and conclusions in the new knowledge areas developed. Teaching presence in an online learning process refers to the process whereby the teacher plans and designs the course, and instructions facilitated through a medium of communication. Concerning professional de- 
velopment, Case $\mathrm{H}$, pointed out that she has developed abilities to learn and construct knowledge with others in a virtual learning environment. Online features helped me to set my learning goals, make sure I have feedback through assessment and equally involve myself in teaching/learning activities.

\section{Self-Learning Mode (SLM) and Professional Development}

Case A: Case A defined Social presence in DED learning manuals as the extent to which the material or content of manuals have a direct impact on the individual and the society. DED learning manuals have contributed satisfactorily in professional development. They clarify the cloudy nature of some concepts. They have made one to feel a teacher even out of class. Concerning cognitive presence in DED learning manuals, Case A refers to it as the extent to which the material in the manuals meets the logical needs of the learners. He further explained that the manuals have greatly inspired a lot of thinking even after the course because he still consults the manuals when preparing lessons. Teaching presence in DED learning manuals refers to the extent to which the manuals as instructional materials meet the learning needs of the learner. The manuals have reinforced my capacity to teach without difficulties.

Case B: According to Case B Individual social presence in DED learning manual simply means using manuals to study alone. Social presence in DED learning manual greatly contributed to my professional growth. It helped me to develop skills to learn, follow up lectures even without the physical presence of the teacher. To Case B, Cognitive presence in DED learning manual means reflecting on what you are studying. Cognitive presence in DED learning manuals improved my professional development. After studying the manuals, I reflect on the materials I come across. Teaching presence in DED learning manual means using the manuals as if you are interacting with your instructor physically. The manuals seem to me like the instructor. I like to read it several times.

Case C: To Case C Individual social presence in DED learning manuals refers to feeling of togetherness between the students through the use of learning manuals. My personal social presence with DED learning manuals has helped to widen my scope of reading, search for information and learning with these manuals. Cognitive presence in DED learning manuals means reflection and thinking processes when using DED manuals. Cognitive presence in DED learning manual has helped to increase my thinking processes as regard theories of learning. Teaching presence in DED learning manuals means facilitation of learning through the use of DED manuals. Teaching presence in DED manuals has increased the usage of these manuals as teaching learning materials.

Case D: Case D viewed Social presence in DED learning manuals as the extent to which the learner interacts with the learning activities and the content of the manual. The social presence in DED learning manuals contributed to my professional development. Concerning how I used DED learning manual, I read each unit line after line. I make summaries and answer questions on each unit. I use to write exams without stress. Cognitive presence in DED learning manuals helped 
in my professional development. My age and teaching experience for fourteen years helped me to read well and understand the content of the manuals. Concerning teaching presence in DED learning manuals, I must say that the manuals were well explicit enough for easy understanding. The teaching presence in DED learning manuals influenced my professional development. The teachers were down to earth. They were explicit and always teach using teaching aids and examples. They taught us as individuals, in groups and this facilitated the teaching learning process. We need DED in masters.

Case E: According to Case E, social presence in DED learning manuals refers to the feeling of belonging with DED learning materials. The social presence in DED learning manuals increased my reading habits or culture. Cognitive presence in DED learning manuals refer to reflection and thinking when using DED learning materials. The cognitive presence in DED learning manuals helped me to construct positive attitude toward learning. Teaching presence in DED learning manuals refers to the facilitation of learning when using DED learning materials. It increased my scope and knowledge of teaching methods.

Case F: To Case F social presence in DED learning manuals refers to an individual perception of herself based on experience and interactions with the outside world and learning manuals. The social presence in DED learning manuals contributed to my professional development in that, it served as a foundation for building confidence in my professional competences and learning experiences. It helped me to learn how to deliver instructions in class effectively. Cognitive presence in DED learning manuals refers to the learner's ability to think critically, collaborate in problem solving and construct meaning with the aid of learning manuals. Thanks to DED learning manuals I developed the motivation to learn at my own pace. This has helped me to develop the ability to conceive and implement new ideas. The content in the manuals is very rich and well organized for learning at anytime and anywhere. Teaching presence in DED learning manuals consists of a teaching/learning procedure in which content, instructional technology, and pace of learning are based upon the abilities and interest of each learner in a context that make sense to them with the use of learning manuals. Since instructions are designed to meet the needs of the learner, my experience with DED manuals has helped me to understand my pupils needs by identifying their strength, skills, challenges, preferred learning styles and interests.

Case G: According to Case G, social presence in DED learning manual refers to the way the learner relates or interacts with learning content and learning activities in the manual. DED learning content has helped me to improve on my instructional effectiveness, social context in classroom, online communication and interactivity in course work. Cognitive presence in DED learning manuals refers to the extent to which a group of learners are able to construct meaning through sustained interaction with the learning content, suggested links and documentations. DED learning manuals are designed to support thinking. This 
has essentially helped me to develop research and analytical skills. It has also helped me to develop critical thinking skills. Teaching presence in DED learning manual refers to designing, facilitating, and directing of cognitive and social processes for the purpose of realizing meaningful and worthwhile learning outcome, through the learning of content, using links. I have been able to use DED learning manuals for instructional design and evaluation.

Case $\mathrm{H}$ : Case $\mathrm{H}$ states that social presence in DED learning manual refers to a situation where an individual uses his/her manuals to come out with meaningful information. References can be made from the manuals where the individual can login to some programmes and interact with others, for example through twitter, WeChat, messenger in order to communicate and share learning ideas. The social presence in DED learning manuals contributed to my professional development as I am now able to do a lot of research from references cited in the DED learning manuals and this goes a long way to enhance my professional development. Cognitive presence in DED learning manual refers to the ability of learners to think critically, collaborate in problem solving and construct meaning with the aid of DED learning manuals. Through DED learning manuals, my thinking ability has been improved. Critical thinking helps me in problem solving and I equally construct meaning from related concepts and theories learned in DED learning manuals. Teaching presence in DED learning manual consist of the process whereby the instructor uses DED learning manuals during a teaching/learning process. He gives directives and instructions based on what the manual demands (Table 2).

\section{Conclusion and Recommendations}

Overall, this study revealed that blended learning model influenced the professional development of university students in Cameroon. The results have shown that face-to-face learning mode, online learning mode and self-learning mode contribute to professional development of students at different rates. The findings have also shown that students are more comfortable with face-to-face learning mode as compared to online learning mode and self-learning mode. The study offers new evidence as well that the blended learning model is real in the University of Buea and has the potential to respond to diverse needs of learners in higher education. It also has the potential to help students to learn better and develop their professional skills and competences. The model is out to promote work-study programmes which can help students to finance their studies and improve on their capacities at the job sites. With this model, students are able to connect theoretical studies with practical reality in the field. Based on the results of the study, the following recommendations are made to universities:

1) Universities should adopt this model for professional development.

2) The curriculum for higher education should be reengineered in order to accommodate this new approach of content delivery and assessment. That is a complete review of critical processes and redesign of those processes should be 
Table 2. Summary presentation of the results.

\begin{tabular}{|c|c|c|c|}
\hline BLM & Determinants & Description & Professional Development \\
\hline \multirow{3}{*}{ FFLM } & $\begin{array}{c}\text { Social } \\
\text { Presence } \\
\text { during } \\
\text { tutorials }\end{array}$ & $\begin{array}{l}\text { Affective dimension of tutorials. } \\
\text { Interactions between the learner and the tutor } \\
\text { in a confined environment. } \\
\text { Interactions with friends and teachers. } \\
\text { Feeling of belonging in class or group } \\
\text { Ability to identify with the group or course, connect, } \\
\text { express one's feelings and emotions and interact } \\
\text { with others as real people } \\
\text { Communication that foster personal and purposeful relationships } \\
\text { Measure of the feeling of community that the learner experiences. } \\
\text { Combination of factors that leads to development } \\
\text { of greater intimacy and immediacy. }\end{array}$ & $\begin{array}{l}\text { Improvements in public speaking, logical argument. } \\
\text { Improvements in exam grades. } \\
\text { Change in the perception of the learner as an } \\
\text { empty vessel to someone with potentials. } \\
\text { Improvements in teaching skills. } \\
\text { Expansion of levels of interactions and scope } \\
\text { of learning and thinking. } \\
\text { Development of networking abilities. } \\
\text { Open to continuous professional development } \\
\text { opportunities. }\end{array}$ \\
\hline & $\begin{array}{c}\text { Cognitive } \\
\text { presence } \\
\text { during } \\
\text { tutorials }\end{array}$ & $\begin{array}{l}\text { Levels of learner reflection and thinking in the lesson. } \\
\text { Levels of acquisition of new knowledge. } \\
\text { Deep reflection and thinking processes during tutorials. } \\
\text { The extent to which learners are able to construct and confirm } \\
\text { meaning through sustained critical and collaborative thinking. } \\
\text { Critical thinking in the course of exchange of ideas in a group. } \\
\text { Problem-solving that leads to exploration, construction, } \\
\text { resolution and confirmation of understanding. } \\
\text { Level of thought or thinking that the tutorial } \\
\text { subjects the learner to. }\end{array}$ & $\begin{array}{l}\text { Development of abilities to teach with stress. } \\
\text { Language development. } \\
\text { Improvements in lesson presentation skills. } \\
\text { Improvements in problem-solving skills, analytical } \\
\text { skills, assessments and evaluation skills. } \\
\text { Subjective thinking to objective thinking. }\end{array}$ \\
\hline & $\begin{array}{l}\text { Teaching } \\
\text { presence } \\
\text { during } \\
\text { tutorials }\end{array}$ & $\begin{array}{l}\text { Physical presence in class. } \\
\text { Question and answer activities in a normal class situation. } \\
\text { Sharing of personal experiences and ideas in a physical classroom. } \\
\text { Tutor use of real teaching aids. } \\
\text { Facilitation of learning by a live teacher. } \\
\text { Real instructional relations tutors have with learners. } \\
\text { Tutors remain as models to the learners. } \\
\text { Teachers design instructions, facilitates discussions } \\
\text { and give direct instructions to the learners. } \\
\text { Ability of the tutor to facilitate learning through guidance, } \\
\text { direct instruction and assistance. }\end{array}$ & $\begin{array}{l}\text { Development of innovative skills. } \\
\text { Facilitation of learning. } \\
\text { Construction of research skills. } \\
\text { Improvements in instructional skills. } \\
\text { Development of models at the jobsites. }\end{array}$ \\
\hline \multirow[t]{2}{*}{ OLM } & $\begin{array}{l}\text { Online social } \\
\text { presence }\end{array}$ & $\begin{array}{l}\text { The learner and the tutor are not on one site but linked } \\
\text { by the Internet. } \\
\text { Interactions between the learner and the instructor through ICTs. } \\
\text { Feeling of belonging in the learning process through the Internet. } \\
\text { Ability of learners in a learning community online to } \\
\text { project themselves, socially and emotionally as real people. } \\
\text { Communications online that foster interpersonal } \\
\text { and purposeful relationships. } \\
\text { Developing the sense of belonging in distance education. }\end{array}$ & $\begin{array}{l}\text { Ability of the learner to see beyond the immediate } \\
\text { environment and present. } \\
\text { Positive attitude towards learning online as it is faster } \\
\text { and cost effective. } \\
\text { Construction of independent research skills online. } \\
\text { Development of interest in online research. } \\
\text { Acquisition of knowledge about different learning } \\
\text { patterns and styles. } \\
\text { Construction of collaborative and cooperative skills. }\end{array}$ \\
\hline & $\begin{array}{l}\text { Online } \\
\text { cognitive } \\
\text { presence }\end{array}$ & $\begin{array}{l}\text { Use of ICTs to facilitate learning. } \\
\text { Learner ability to understand the tutor's instructions online } \\
\text { Reflections and thinking when using the Internet for learning. } \\
\text { Quality and quantity of critical thinking, collaborative } \\
\text { problem-solving, and construction of meaning through } \\
\text { personal and interpersonal interactions online. } \\
\text { Critical thinking in the course of exchange } \\
\text { through an electronic device. } \\
\text { The extent to which learners are able to construct, confirm } \\
\text { and sustained meaning in a critical community of inquiry. }\end{array}$ & $\begin{array}{l}\text { Development of creative and innovative skills. } \\
\text { Widens the learner's scope of knowledge and thinking. } \\
\text { Improvements in communication and sharing skills. } \\
\text { Improvements of professional competences. } \\
\text { Achievements of educational goals objectives. } \\
\text { Interest in learning course material. } \\
\text { Interest in using the internet for research. } \\
\text { Positive attitude towards distance education. } \\
\text { Help learners to connect theory with practice. } \\
\text { Promotion of thinking and internationalization of } \\
\text { content, analytical skills, inquiry-based learning, } \\
\text { problem-solving skills, assessments skills. }\end{array}$ \\
\hline
\end{tabular}




\begin{tabular}{|c|c|c|c|}
\hline & $\begin{array}{l}\text { Online } \\
\text { teaching } \\
\text { presence }\end{array}$ & $\begin{array}{l}\text { Use of Internet in learning. } \\
\text { Process of facilitating learning online. } \\
\text { Design, facilitation, direction of cognitive and social } \\
\text { processes to realize meaningful learning outcomes } \\
\text { through an electronic device. } \\
\text { Process whereby the teacher plans instructions, prepares } \\
\text { content and learning takes place through an electronic tool. }\end{array}$ & $\begin{array}{l}\text { Learner develops problem-solving abilities. } \\
\text { Prioritize learning and the learner. } \\
\text { Acquisition of skills, concepts and procedures } \\
\text { for developing content. } \\
\text { Improved planning and definition of learning goals. }\end{array}$ \\
\hline & $\begin{array}{l}\text { Social } \\
\text { presence } \\
\text { in DED } \\
\text { learning } \\
\text { manual }\end{array}$ & $\begin{array}{l}\text { The extent to which the content meets the needs of the learner. } \\
\text { Self-learning with study manual } \\
\text { Feeling of togetherness when using the study manual. } \\
\text { The extent to which the learner interacts with } \\
\text { the learning activities and content. } \\
\text { An individual's perception of learning based on experience } \\
\text { and interactions with the study manual }\end{array}$ & $\begin{array}{l}\text { Increase in research abilities and reading culture. } \\
\text { Served as foundation for building confidence in } \\
\text { professional competence and learning experiences. } \\
\text { Improves instructional knowledge. }\end{array}$ \\
\hline SLM & $\begin{array}{l}\text { Cognitive } \\
\text { presence } \\
\text { in DED } \\
\text { learning } \\
\text { manual }\end{array}$ & $\begin{array}{l}\text { The extent to which the content meets the cognitive } \\
\text { needs of the learner. } \\
\text { Reflections and thinking processes when using the study manual. } \\
\text { Ability to think critically, collaborate in problem solving } \\
\text { and construct meaning with the aid of the study manual. }\end{array}$ & $\begin{array}{l}\text { Increase in thinking abilities. } \\
\text { Contribute to building a positive attitude } \\
\text { towards learning and the profession. }\end{array}$ \\
\hline & $\begin{array}{l}\text { Teaching } \\
\text { presence } \\
\text { in DED } \\
\text { learning } \\
\text { manual }\end{array}$ & $\begin{array}{l}\text { The extent to which the manual meets the learning } \\
\text { needs of the learner. } \\
\text { Facilitation of learning when using the manual. } \\
\text { Interactions with the content. }\end{array}$ & $\begin{array}{l}\text { Reinforcement of capacity to teach without difficulties. } \\
\text { Increase scope of knowledge in teaching } \\
\text { methods and techniques. } \\
\text { Contributes to self-learning. }\end{array}$ \\
\hline
\end{tabular}

made to make them more efficient and able to deliver higher quality (Noe, 2002).

3) Teachers should be trained on the didactics of blended learning model in order to do their job effectively.

4) Teachers should be trained on the development of the curriculum for blended learning model. They should be trained on how to plan, design and develop the curriculum, how to deliver contents and how to carry out assessments.

5) Universities should move closer to the students and not the students coming and overcrowding one single campus. For this reason, study centers should be created at different locations where students can have face-to-face interactions with tutors and classmates. The study centers should be equipped with adequate and relevant infrastructure to manage the students.

\section{Conflicts of Interest}

The author declares no conflicts of interest regarding the publication of this paper.

\section{References}

Alemnge, F. L. (2015). Distance Education at the University of Buea, Cameroon. Journal of Educational Policy and Entrepreneurial Research (JEPER), 2, 34-42.

Guglielmino, L. M., \& Guglielmino, P. J. (2004). Becoming a More Self-Directed Learner: Why and How. In G. M. Piskurich (Ed.), Getting the Most from Online Learning (pp. 
25-38). San Francisco, CA: John Wiley and Sons.

Kritsonis, A. (2004-2005). Comparison of Change Theories. International Journal of Scholarly Academic Intellectual Diversity, 8, 1 .

Latchem, C. (2012). Quality Assurance Tolkit for Open and Distance Non-Formal Education. C.O.L.

Locke, E. A. (1968). Towards a Theory of Task Motivation and Incentives. Organizational Behavior and Human Performance, 3, 157-189. https://doi.org/10.1016/0030-5073(68)90004-4

Naidu, S. (2003). ELearning: A Guide Book of Principles, Procedures and Practice. New Delhi: CEMCA (Commonwealth Educational Media Centre for Asia).

Noe, R. (2002). Employee Training and Development (2nd ed.). New York: McGraw-Hill.

Perkinson, R. (2005). Beyond Secondary Education: The Promise of ICT for Higher Education and Lifelong Learning. In World Bank (Ed.), E-Development: From Excitement to Effectiveness (pp. 101-125). Washington DC: World Bank.

Rwagasana, G., \& Stucki, P. (2009). Strategic Options and Results of Introducing Blended Learning at the National University of Rwanda. eLearning Africa 2009: 4th International Conference on ICT for Development, Education and Training, Dakar, 27-29 May 2009, 66-69.

Sagna, O. (2005). Lifelong Learning in the African Context: A Practical Example from Senegal. In C. McIntosh (Ed.), Perspectives on Distance Education, Lifelong Learning and Distance Higher Education. Paris: UNESCO/COL.

World Bank (2006). Information and Communication for Development: Global Trends and Policies. Washington DC: World Bank. 